\title{
Pandemic Response: Risk Planning in Times of a Crisis
}

\author{
Lucas Engelhardt \\ United International Business Schools in Amsterdam
}

\author{
Alasdair White \\ United International Business Schools
}

\begin{abstract}
The COVID-19 crisis caught many economic players unprepared and unable to act. Little research has been conducted on its impacts and reasons for the lack of appropriate countermeasures. This paper investigates the progress of the crisis and analyzes potential reasons for the emergence of unsatisfactory risk management. It gives advice for companies on how to cope with the situation best. In addition to the current situation, two past crises as well as the contrary strategies of two companies were examined with the aim of drawing sensible conclusions towards their strategies of managing risk. Modern methods with a strong focus on data-driven examination lead to one-dimensional approaches that are unable to reflect complex interrelations. The paper concludes that existing risk management systems are already set up in a comprehensive way and that the main issue lies within behavioral patterns of individuals who are either unable or unwilling to see existing risks. This leads to situations in which risks are identified, though concurrently ignored in subsequent decision-making processes.
\end{abstract}

Keywords: risk management, COVID-19, Lehman Bros, Volkswagen

\section{INTRODUCTION}

"There are three kinds of lies: lies, damned lies and statistics." Even though the infamous quote attributed to Benjamin Disraeli, former Prime Minister of Great Britain in the 19th century, may seem exaggerated and partially striking at first sight, it comprises more truth than most fanatics of numbers are willing to admit. Statistics developed into a science that enables humans to process large quantities of data, to recognize certain patterns and to draw sensible conclusions. However, data on its own is not worth a lot. When the basic concepts of statistics were developed, the people developing them neglected the relevance of causation and started to propagate the false belief that the answers to almost all scientific questions lay in the data alone. From that point in time, all attempts challenging that concept were avowed as unscientific and therefore never managed to hit the surface (Pearl and Mackenzie, 2018, p.5). The concepts of statistics and managing risks are closely connected in today's world. The idea of managing risk is not a new phenomenon, but the general understanding changed fundamentally throughout history. Risk not only applies to economic contexts but rather is a big part of our daily life. However, corporate actions in particular are characterized by risk and companies are used to operating under a high level of uncertainty. Taking chances and accepting the possibility of negative outcomes lies at the heart of every entrepreneurial entity (Weber, Weißenberger and Liekweg, 2001). With high risk comes high reward but losing the balance and accepting 
risks of which the consequences are severe, contradicts the mindset of the so-called "homo economicus", that bases its actions on a rational way of thinking (Cramer, 2002). This paper aims to analyze possible reasons for the failure by comparing aspects of successful and unsuccessful corporations of the past. The focus lies on the examination of dissimilar approaches towards handling risk and proposes an adapted methodology that could be the solution to handling the multifaceted environment of the contemporary business world. With the ongoing global COVID-19 pandemic, the research is very relevant and contributes to developing possible short-term solutions as well as providing thought-provoking impulses on a rather longterm, strategic level, as the current situation will most probably not be the last of its kind. This paper takes the ongoing COVID-19 pandemic crisis as an example to point out its unique characteristics compared to previous disasters and connects the newly generated findings to those in order to draw sensible conclusions that constitute a helpful framework for companies to follow and build a solid foundation for their future actions. The development of the framework is based on the most recent literature in the field of cause and effect, which guarantees the results to be cutting-edge and unparalleled in the area of risk management.

\section{CASE STUDY: LEHMAN BROTHERS VS. VW}

This section we analyze two companies that experienced the financial crisis of 2007 to 2009 with drastically different outcomes in order to draw conclusions from their behavior with a special focus on their approaches towards risk management. Starting with Lehman Brothers Holding Inc., the story of their downfall was at the center of any media coverage at that time. The reasons for their eventual failure are manifold but can mainly be traced back to the individual misbehavior of senior management as the following breakdown will outline. Starting with the external factors that drove the collapse, the governmental influence needs to be mentioned. The initial change of laws enabled the situation to develop in the way it did. However, it is hard to make the government responsible for this specific case because they did not force anyone to take advantage of their adaptations. Nevertheless, Lehman Brothers were not the only investment bank struggling to survive at that time. Bear Stearns experienced a similar development but was eventually saved by a takeover by J.P. Morgan Chase which was financially back by the US government. For Lehman Brothers, such extraordinary measures were not activated which left them in a free fall that led to a never-before loss for the American bank as well as the global economy (Wiggins, Piontek and Metrick, 2014).

The analysis of the internal factors provides deeper insights on their operative decisions and helps to better understand the real reasons behind their collapse. Up until 2006, they willingly increased the risk of their business by aggressively investing in real-estate assets with a special focus on commercial real estate and subprime mortgages which simultaneously provided them with a high leverage (Valukas, 2010). This approach seems even riskier when taking the level of their equity into account. The relation of their equity to total capital was at 3 percent (Fessler and Hinsch, 2013). Although, there is no scientific consensus on the value of an ideal ratio, most authors agree that a percentage below 20 is too risky to pursue and will lead to the destruction of a company in case of any negative event happening (Compeon, 2020; Forster, 2016). However, the possible profits from that strategy were disproportionately high in a situation where nothing goes wrong, but when a crisis occurs it is difficult to turn tangible assets into money. Considering the size of the company, it is incomprehensible that they were willing to accept the risk and gamble on an ever-growing economy by radically underfunding the company.

Lehman Brothers had problems with managing their risks for a long time. The Russian financial crisis of 1998, even before the dot-com crisis, led to a situation in which they were very close to being bankrupt (BBC News, 1998). Consequently, in 1999 they hired Madelyn Antoncic, a risk management expert with extensive experience in the sector. She was charged with establishing a functioning risk management infrastructure within their existing processes. Her efforts were so successful, that she and her framework were honored in 2006. It combined the use of quantitative and qualitative measures, as well as continuously analyzing any internal and external developments that affect the company (Wiggins, Piontek and Metrick, 2014). Antoncic's model provides a sensible explanation for why their risk-heavy operations after 1999 worked out as well as they did, helping the company to grow without experiencing setbacks. 
However, Antoncic later claimed that the senior management of Lehman Brothers developed a deep resistance towards risk management after 2006 and they decided to go back to their old approach that almost led to their bankruptcy in 1998 (Wharton University, 2018). Others agree by saying that their risk management practices mostly existed on paper but hardly in practice (McDonald, 2013). In 2006, the risk management model strongly indicated alarming conditions in the real estate market that were not taken seriously but were, rather, overruled by executive management of the company. Besides that, their overall behavior prior to the crisis lowered their flexibility in case of a crisis and this further worsened the situation (Wharton University, 2018). Despite all the warnings and the start of the obvious decline in prices of real estate in 2006, Lehman Brothers decided to remain faithful to their 'proven' strategy by maintaining their level of investment in even riskier ways into real estate and subprime mortgages, which had already lost most of their inner value at that time (Wiggins, Piontek and Metrick, 2014). Even after the situation fully unfolded the CEO at that time, Richard Fuld Jr., did not seem to recognize the existence of any false decisions on his part and kept on defending his actions by blaming others for everything bad that happened (Gass, 2015). Additionally, he maintained a rather toxic relationship with the government as a result of his reckless and self-centered behavior and many outsiders understood the decision to not bail out Lehman Brothers as a political one with the aim of seeing Fuld fall together with the company. From a risk management perspective, it can be seen as a very poor strategy to maintain a toxic relationship with a federal agency upon which the company relies heavily.

Even though, the external influences created a situation that allowed the events to happen in the way they did, the internal processes together with the individual behaviors and attitudes of senior management are to blame for the bankruptcy of Lehman Brothers. It is astonishing to see that despite having an awardwinning risk management system implemented, that enabled them to take high risks and record disproportionately high profits, they still managed to resist following the logical path. By being able to operate in such a risky way from 1999 to 2006, allowed a belief to develop in the company that nothing could go wrong. The executives of the company even overruled their proven and trusted risk management expert, Madelyn Antoncic, who repeatedly discouraged them from taking even more risk starting in late 2006. This shows that they were only focused on even higher profits and trusted in ever-growing housing prices which ultimately diluted their awareness of potential negative outcomes. In the period of their successful risktaking, a culture of excessive risk-taking must have been established within the company, resulting in a scenario where almost everyone had a similar affinity for risk. Moreover, it is possible, that their fast expansion in the early 2000's made their internal structures highly complicated and hard to manage. Considering they were close to bankruptcy due to similar reasons in 1998, it is difficult to comprehend how obvious signs of future negative developments can be ignored in such a manner.

The analysis of Volkswagen AG shows a drastically different result of handling the financial crisis even though they were impacted heavily as well. Thirteen years previously, just before the crisis started, their Japanese competitor, Toyota, occupied the spot as the biggest car manufacturer in the world, but VW was catching up quickly before the financial crisis struck, harming the achievement of their goal. However, they managed to turn that situation around and kept on growing (Volkswagen, 2020). This begs the question what helped them to cope with that situation better than others. One would assume that it can be traced back to a multitude of factors. The analysis shows that some of those factors were within their power whereas others were not. To start with the external factors, the German government did everything they could to prevent the company from going bankrupt and by doing so, protected an important pillar of their economy. Having said that, VW always maintained good relations to the government and many outside experts suspected them of pressure politics in order to achieve decisions in their favor. Many insiders confirm the close and, to put it mildly, special relationship (Bannas and Germis, 2015). The German government was a willing participant in this and, following the economic shock, the "Abwrackprämie", or scrappage premium, a subsidy released in 2009 with the aim of boosting the sales of new cars, was established. In addition to that, the introduction of facilitations for short-term work constituted an immense relief of pressure for Volkswagen as well. The main target was to secure the employment of workers and prevent a nation-wide mass redundancy. Moreover, Volkswagen benefitted highly from the emerging economies of the Asian and South Pacific region. As their economies were not very hard hit by the financial crisis, they served as a 
buffer to compensate for the decline in demand from the European and American markets (Focus, 2010). Their efforts of spreading their risk by not relying on a single market or geographic region payed off and turned out to be a primary factor of their survival.

The analysis of internal factors leads to their strong risk management system that was established long before this crisis and even prior to the dot-com bubble. In their approach they considered a multitude of internal and external risks: individual, macroeconomic, industry, research and development, suppliers, demand-related, quality, personnel, legal, environmental protection, financial, liquidity, IT and more. In addition to that, they regularly conducted a comprehensive analysis of global economic developments and the impact of those for their business and continuously advanced their systems in order to be even better prepared (Volkswagen 2006, pp.102). They further developed their systematic risk management system, helping to identify risks and react accordingly. In order to always be on top of any risk, they established an annual, cyclical control process that also includes governance and compliance guidelines and is based on the international COSO framework.

Additionally, it is split into three different levels which focus on the operational and strategic risks as well as the continuous monitoring of the overall risk-structure and the effectiveness of the measures that are taken (Volkswagen 2016, pp.181). Moreover, risk scores are being calculated using the severity and probability of occurrence. In order to enhance the significance of their research, they add qualitative measures to the quantitative ones as well by creating risk-scores that are portrayed in a portfolio diagram (Volkswagen 2019, pp.165). However, Volkswagen themselves acknowledge the fact that it is close to impossible to prepare for completely random and unforeseeable events such as the collapse in 2008 or the current COVID-19 pandemic which can, despite the comprehensive risk management system, have severe impact on the viability of the company (Volkswagen 2007, p.169). A big difference compared to Lehman Brothers can also be seen in the approaches of funding the company. Prior to the crisis in 2006, VW had a relation of equity capital to total capital of 19,7 percent which was even raised to 22 percent in 2007 (Volkswagen 2007, pp.130). Taking into account the opinions of several authors, a percentage like that normally indicates a further growing trend as well (Compeon, 2020; Forster, 2016). This can also be seen as part of risk management as it creates a buffer against potential losses in the future and provides assistance for the survival of a company. VW has made use of that ever since and incorporated it as an important variable into their risk management approach.

One could assume that this behavior correlates with the German mentality of being rather realistic and risk-averse which results in an urge of wanting to be prepared as good as possible for any outcome and reducing risk as much as possible in a proactive manner. However, this contradicts VW's "Dieselgate" affair that surfaced in late 2015 just as they were about to overtake Toyota and become the market leader. VW manipulated the emission control systems of their cars in such a way that they met the legal requirements for maximum output of emissions only when connected to the testing software. Consequently, they were accused of deception by their customers and were accused of restraint on competition (Hotten, 2015). Retrospectively, they admitted, that the first manipulated car was sold in 2008, resulting in at least 7 years of fraud (Reuters, 2015). Even though they were aware of the high risk they were taking and ignored several warnings from key suppliers like Robert Bosch $\mathrm{GmbH}$ as well as internal experts, management still opted for the software (Arvinth, 2015; Bergermann, 2018). Ironically, the people in charge who were responsible for the events even received millions in compensations for being dropped by the company (Davies, 2016).

All in all, the survival of Volkswagen was assured by a combination of governmental intervention and thoughtful preparation in context of their risk management approach. Even though, they were not able to fully foresee it, it is unlikely that that is due to ignorance or underestimation. For that to be true, the efforts Volkswagen puts into managing risks annually is too high and would constitute fully irrational behavior. Having said that, their behavior post 2009 shows that they are also capable of ignoring rational decisionmaking whilst only focusing on the benefits and keeping up the belief that everything will always go right. 


\section{ANALYSIS OF NATIONAL RISK MANAGEMENT APPROACHES}

The WHO was aware of the potential risk of an epidemic outbreak and communicated that to the global community. In 1999, the first document was released, serving as a guideline for national and regional planning in case of an influenza pandemic (WHO, 1999). It contains recommendations on behavior in the different stages of a pandemic as well as the supporting activities that are needed. In that document, the importance of risk management was emphasized even further. The creation of the "Pandemic Influenza Preparedness (PIP) Framework" underlines the efforts taken to be ideally prepared for such a scenario to materialize (WHO, 2017a). The document proposes a collaborative approach which puts high emphasize on being prepared as well as possible in order to be able to react as fast as possible (WHO 2017, pp.27).

As of 2020, the WHO had 194 member states, leaving a marginally small number of regions worldwide as non-members (WHO, 2020). Therefore, one could assume that the message was spread in an exhaustive way, leading to most countries taking serious precautionary actions as the consequences of such a scenario are severe in any way. In addition to the documents released by the WHO, which underscore the severity of the topic, many experts released papers that can retrospectively be seen as serious warnings for every human being. Even though a pandemic is considered to be an event that brings high levels of uncertainty and is unpredictable in many ways, the warning signs were too obvious to ignore. It was unequivocally apparent that it was not a question of if, but rather a question of when the next pandemic will occur. In 2005, Michael Osterholm, a globally renowned disease expert, pointed out the urgency of the matter following the SARS pandemic and asserted that action must be taken now. Shortly before COVID-19 surfaced, the virologist Robert Webster added his concerns by predicting another virus like the influenza in 1918 would occur soon (Webster, 2018). Adding to that, the Global Preparedness Monitoring Board (2019, p.15) added in their latest annual report, dating back to September 2019, that the world is not ready for a fastmoving pandemic.

Even the U.S. government took part in warning the public by publishing articles via the US Intelligence Community (IC) that unambiguously outlined the potential threats of a disease with severe global social and economic impact (IC, 2019). In 2018, the former director of medical and biodefense preparedness declared a possible pandemic as the most relevant health security concern. Additionally, she pointed out that the world is far from being prepared for an actual outbreak (Sun, 2018). The list of people and entities giving out warnings was close to being endless and even the U.S. government itself investigated the topic and was aware of the danger, however they seemed to fail to see the urgency of the matter. Their risk management systems are manifold, and they even possess one that is solely focused on hazards for public health. However, when the results and recommendations for action are being ignored, even the best system loses its purpose.

Similar to the United States, Germany also has an extensive and specialized risk management approach in place, one that plays an important role in terms of their strategic management (BBK, 2020). In addition to that, the Robert Koch Institut (RKI), a federal government agency, was appointed to be in charge of the control and prevention of diseases and it regularly releases thoroughly compiled plans in case of a pandemic (RKI, 2019). Moreover, in 2013, the German parliament (Deutscher Bundestag) released a report covering the risk analysis of civil protection that contained a scenario by the name of "Pandemic caused by virus Modi-SARS" (Deutscher Bundestag, 2013). Strangely, the seven-year-old report seems to predict the current COVID-19 pandemic situation very precisely because it is more difficult to find differences than it is to find similarities. However, compared to most countries, Germany has the advantage of having an advanced and well-funded healthcare system possessing one of the highest rates of hospital beds and medical personnel relative to the population, and this constitutes an immense benefit now (The World Bank, 2020; The World Bank 2020a). Moreover, being one of the biggest and wealthiest economies enabled extensive spending on ad hoc actions such as widespread testing and the building of emergency facilities. Therefore, they managed to absorb the shock in a comparably positive way, however, there were no concrete measures in place. Despite the strength of the healthcare sector, the system came very close to collapsing. The situation in Italy and other regions of the world enabled the government to conduct a detailed analysis and to learn from the mistakes that were already made. 
The concepts of inference and causation, that are covered in the early sections of the paper, are of importance in this context as well. Even though, most governments do deploy comprehensive risk management systems, they still seem to overlook the importance of causation in a broader perspective. As most political decisions are based on achieving economic benefits, it would make sense to conduct more detailed analyzes that uncover a higher number of risks that could potentially result in economic impacts. Weighing up the costs of proactively taking adequate preparations in case a risk materializes with the costs of mitigating the risk reactively would result in an improved level of preparedness in most cases. The combination of the negligence of the concept of causation and the underestimation of risk with respect to the severity and probability of occurrence constitute the major weaknesses of the widespread normative theories of modern economics.

Taking all the arguments above into account, it is hard to comprehend how such a small number of countries were prepared when the pandemic finally hit. It is difficult to say if even one country was prepared sufficiently or if it was rather the existence of a variety of fortunate circumstances that positively influenced their ability to cope with the situation better. The majority of countries underestimated the real risk of a pandemic in spite of the fact that various wide-ranging risk management systems existed that analyzed the situation not only based on numerical values but combined with several qualitative and quantitative methods to monitor global developments.

\section{LESSONS LEARNED FROM PREVIOUS CRISES}

The comprehensive analysis of previous crises as well as the COVID-19 crisis and the actions of companies and governmental institutions taken, leads to the development of multiple conclusions that provide input to answer the initial research question. Based on the results, the research questions call for a differentiated approach for answering them. The preceding analysis demonstrates that risk management itself is very useful and indispensable for companies and countries to be successful in the long term. The research objects have comprehensive systems deployed which contain a combination of quantitative and qualitative measures, likewise, allowing an extensive approach that covers a multitude of influencing factors. Therefore, in order to foresee crises and prepare accordingly, the more sophisticated the system is, the higher is the probability of detecting certain trends early. In every case analyzed before, the risk management system was able to sense negative developments that eventually led to the outbreak of a crisis.

Due to that, risk management goes further than just saving money and hoping for the best. In order to increase the effectiveness of any risk management system, companies should integrate as many factors as possible and add unconventional methods to the conventional ones to be best prepared for possible future happenings. The example of Volkswagen underlines the importance of thinking outside the box with them maintaining close relationships to the German government which helped them to cope with the aftermath of the "Dieselgate" and to minimize the negative impact. If their misbehavior had been detected in Germany instead of the United States, it is not certain that the case would have even been pursued as it has been. Additionally, the build-up of appropriate funding, with regard to the ratio of equity to total capital, is of high importance and can be seen as a risk management strategy. The capital can act as a buffer to absorb the shock of declining demands and missing profits. Therefore, the author is forced to conclude, that the mistakes being made in risk management are not based on the application of rather one-dimensional methods because even when particularized systems are in place, bad outcomes are apparent. Moreover, it is evident, that these systems do produce satisfactory and worthwhile results. Even though most risk management systems do neglect the importance of specific factors that would support the occurrence of more accurate outcomes, the biggest issue is based on the way individuals treat risk and the ways to deal with possible negative outcomes. As the discussion shows, it is often the case that risk management only takes place on paper and the results are not considered to the degree they should be in the processes of management and decision-making. Therefore, mistakes do happen based on the misbehavior of individuals which can be explained by reason of character traits and psychological aspects which are elaborated in a later section of this paper. As organizational hierarchies tend to narrow from the bottom up, the way risks get treated often depends on the characteristics of a few people who determine the final decision. 
Existing risk management models do have a right to be considered as they produce plausible results that take various factors into account. Besides that, sometimes it is not possible to forecast situations better due to limitations in the ability to collect and understand relevant data. In case of completely random events such as a pandemic happening, this is true in many ways, but in others it can be seen as a poor excuse for insufficient risk management systems and the underestimation of possible outcomes. Moreover, the subjectivity of determining the probability and severity of different influences can bias the results and lead to false conclusions and false prioritizations. The most important fact that explains the emergence of distorted results is the application of normative approaches that heavily rely on elapsed data while neglecting the importance of current developments that change the environment in which a decision takes place. Models of the past are used to squeeze in any situation and avert a sensible forward projection of the data. However, external parameters change regularly, and models are built upon specific assumptions and circumstances that are rarely still valid when being used at a later point in time. Instead of looking at a situation in the sense of how it should be, the perspective needs to be changed in a way that it questions behavioral aspects in the sense of what is really happening and what the reasons for that are. Nevertheless, the models are not fundamentally bad but the neglect of inference and causation and a tunnel vision on theoretic correctness hinders the recognition of evolving external factors.

Furthermore, the analysis shows that in the context of crises that are very difficult or impossible to foresee, it is very hard to prepare as it is unclear how the consequences will look like. As it can be seen in all crises that are based on a factor of randomness, there are always companies and even industries that highly benefit and others that suffer disproportionately heavy. As the effects are arbitrary, the time, the extent and the direction of the impacts (positive or negative) are unpredictable and preparations can only be done in a broad way that covers multiple developments. Even the companies that generally benefit can encounter problems in terms of rapidly increased demand that exceeds their production capabilities or other complications along their supply chain. Naturally, companies do favor rather positively problems like this over ones that threaten their viability. Therefore, it is not possible to prevent such things from happening, but certain preparations can be done. As already mentioned before, being prepared financially by having enough reserves is one of the best strategies to prepare for any random event that might materialize in the future. In addition to that, the establishment of flexible and agile structures can help to deal with quickly changing internal and external influences and allows tailored adaptions of the business model that fit the new setting.

In terms of strategic management, the dissection of the crises and their developments underline the importance and the potential that the application of its procedures provides. Parts of strategic management involve the consideration of risk and they should be intertwined more tightly even beyond the context of possible crises happening. As the aim of it is to secure the future survival of an organization, mitigating potential threats is key for the success of it. Taking the failure of countries to prepare for the COVID-19 pandemic as an example, in most cases they only managed to take the first step of the strategic management process by conducting a strategy analysis. Some might have formulated possible responses such as the Robert Koch Institut in Germany, but no one managed the implementation of effective strategies, hence missing out on the most crucial step. Besides that, the research field of strategic management includes various theoretical models that can be applied but whose extent go beyond the scope of this paper. Besides companies, nations also need to scrutinize their behavior because theoretically, a contract breach towards their population can be seen. As it is their task to ensure the long-term well-being of citizens in exchange for their workforce and taxes, in the case of the Coronavirus they failed to fulfill their obligation.

All in all, the examination highlights the benefits and potentials that risk management systems have. Nevertheless, it becomes very clear which aspects are missing and why the use of them can still lead to bad results. In order to utilize the full potential, several adaptions need to be made and people in charge must open their perspectives towards a more comprehensive approach that allows an investigation beyond the horizon of their personal and traditional lines of thought. The turning away from normative ways of thinking as well as from the ignorance of unambiguous results will be the key aspects for the optimization of the performance of any risk management system. 


\section{BEHAVIORAL ASPECTS THAT FACILITATE THE EMERGENCE OF NEGATIVE OUTCOMES}

As outlined in the previous section, the main reason for bad outcomes of risk management can be traced back to behavioral traits of individuals and the way they deal with the existence of risk. The individual approach to risk is deeply connected to one's personality and character but also gets shaped by the environment a person acts in. Over the course of the development of capitalism, the institution of limited liability might have also encouraged disproportionate risk-taking which could have been intensified even more due to the softened budgetary restraints of enterprises. What facilitates the acceptance of disproportionately high risks even more is the fact that often, decision-makers who are in charge of managing strategic decisions involving risk do not have to carry the responsibility for their actions. In case everything goes according to plan, they receive the full benefits in form of bonuses and glorification. However, if the opposite happens and negative outcomes are apparent, they get exempted from their duties and the mistakes are charged to the company. The VW emissions scandal serves as a perfect example where the managers silently exited the company with millions of euros in compensation in their pockets and leaving behind the chaos they created.

The spreading of neoliberal ideologies around the globe supports this development by making people accustomed to taking risks regularly. The increasing tendency towards a meritocracy does not only support but sometimes requires disproportionate risk-taking in order to not fall behind the competition. Subsequently, the modern economic system relies on certain pillars which become unstable when their foundations start to crumble as the COVID-19 crisis accentuates in a clear way. With the external pressure constantly intensifying, the risk for economic entities (companies and governments) becomes continuously increased and people might feel forced to do things that contradict their personal convictions. Then again, some people could justify their own actions through pushing the responsibility away by perceiving it as just taking orders which would get carried out with or without them. This behavior in situations of moral conflicts was initially documented in 1961 in the so-called "Milgram Shock Experiment" in different contexts and serves as an explanation for actions that contradict rational ways of thinking (McLeod, 2017). The constant feeling of being part of a "winner takes it all" competition rarely produces good outcomes and often leads to questionable behavior in a moral sense.

Therefore, people get used to taking more risk and consequently they subconsciously adjust their perception towards it, making them more tolerant to continuously increasing levels of risk. This goes hand in hand with the belief that nothing can go wrong because it never did before. Lehman Brothers believed they were too big to fall and their CEO at that time willingly increased the risk towards the financial crisis of 2007-2009 despite of clear signs of the emergence of an imminent crisis, and partly justified his behavior with the fact that nothing went wrong in the previous six years. This emphasizes that there is often a strong imbalance between perceived risk and real risk and that the realization of the real developments only occurs when it is too late to act. This is explored by Jared Diamond in his book Collapse in which he considers that this failure to understand problems is a four stage process: (1) The failure to anticipate a problem before it arrives, (2) The failure to recognize as a problem a problem once it has arrived, (3) The failure to attempt to solve a problem once it has arrived and been recognized, and (4) The failure to solve a recognized problem due to the problem or the solution being beyond that capacity or competence of those who must solve it, or is not in their short-term self-interest to do so.

Looking at the current situation, only a marginal proportion of the global population would have ever suspected a situation like this could happen in their lifetime. This can also be traced back to the almost solely positive developments, especially for the western parts of the world, following the Second World War. In terms of the economy and general living standards, major improvements were achieved in the past decades and negative scenarios were far away from the perceived reality because it is more pleasant to

focus on positive aspects only. This also serves as an explanation for why people refuse to even consider examining possible risks in the first place but rather ignore them and take a chance that good developments will result. 
Budgets seem to get allocated for things that are of higher importance at present times rather than caring about sustainable long-term development that requires a sacrifice of quick results in the short term. According to Gilbert (2006), long-term risks typically get underestimated. Often, the reason for that is, that the belief that ad hoc solutions will be found in case such a risk materializes, exists, which produces a fake feeling of safety and represses the urge to take preparatory measures. Again, this behavior underlines the lack of strategic management being applied in practice because, with correct processes in place, it would become clear that long-term developments need to be considered for the future success of any organization. A problem could be that people have turned so egoistical that all they care about are quick results and positive developments within their lifetime or period of accountability. Examples of such behavior can be seen in several areas, outside the context of managing risks in a corporate context, like global warming and the way humans exploit positions of power for instance in the way that most parts of the western world build their carefree and luxurious lives on the shoulders of vulnerable people who are helpless in their positions. This behavior also proves a level of ignorance to adapt to changed circumstances as well as a lack of the ability to learn from mistakes of the past. Similar to the dot-com bubble, the housing bubble was created and currently, regardless of the COVID-19 crisis, American investors act in favor of short-term profits by investing in companies and bleeding them dry afterwards (Pompeo, 2020). By doing so, they manage to leverage exponentially high profits for themselves but leave the companies behind incapable of doing business and severely damage the economy in the long term just as they did in the two preceding crises.

Besides acting in a very selfish way, wishful thinking plays a big role as well. Based on the ideas of Slovic and colleagues (1982), people are willing to accept higher levels of risk for actions in which they see possible benefits being very high. This explains the readiness to sacrifice and take chances for the opportunity of winning big while underestimating the existing risk. Moreover, risks that are easier to grasp get judged more severely than the ones that are uncommon and not a big part of everyday life. If risks have a rather impersonal character and can only be demonstrated on paper or by using simulations, people have problems to project the possible threats to the real world. Even though, the global risk management and research showed clear warnings of a possible pandemic, it was a threat that only a few people could imagine becoming reality and therefore the whole magnitude of it got underestimated by the majority.

As two of many, Kahneman and Tversky (1979) detected the phenomenon of loss aversion as a basic human trait for the process of decision-making. People fear losses more than twice as much as they value gains, hence possible gains need to significantly exceed the value of possible losses for people to even consider taking the risk. However, once the stipulation is fulfilled and the possible gains keep on increasing, people are willing to take disproportionately high risks. In this context, the behavior can be seen with Lehman Brothers and Volkswagen when their actions could have led to extraordinary profits that seemed to exceed any possible risk by far at that point in time. In addition to that, people apply different heuristics to judge risk severity and probability, which are cognitively biased and heavily depend on the overall context and complexity of the situation that needs to be evaluated. It can also be the case that decisions under risk are being made when people do not realize the existence of risk because the chance of it materializing is only marginal. This being the case makes the whole situation even riskier than it already is. However, the important aspect is, that the actual risk a scenario represents is not always equal to the probability of it happening and people tend to neglect risks that are unlikely, judged based on their subjective determination. The problem is, that even though the probability is judged to be low, the severity of the consequences can still be very high. The behavioral aspects described above are also not dissimilar to the ideas of Jared Diamond (2011, pp.420) who analyzed the reasons of societies historically failing to survive in the long term. Even though he looks at a different context, his arguments are very close to the ones developed in this paper and might also lead to the missing ability to manage risks, hence supporting the preceding arguments.

\section{RECOMMENDATIONS FOR ACTION NOW}

When a crisis occurs and no measures and strategies in the context of risk management have been implemented in advance, it is very difficult to act, and it also depends on the extent to which the situation 
influences the corporate operations in positive or negative ways. Either way, current trends need to be monitored closely because the development of the global economy is relevant in both cases and the outcomes are still uncertain. Utilizing current data is more relevant than considering data of the past as the situation is unique. Taking inspiration from the most recent release of Jared Diamond (2019) in which he analyzed the ways of nations handling crises, there are several steps that should be taken. Acknowledging the fact that the crisis exists and cannot be erased is an important step in order to initiate appropriate countermeasures. Organizations need to analyze the situation and find the real causes to be able to adapt their actions accordingly. Decisions should not be rushed, and strategic management can be a key element to develop effective solutions to achieve superordinate goals. Nevertheless, as the world becomes more fastmoving, the planning horizons need to be shortened with the aim of keeping up with current and future developments.

Besides that, the COVID-19 crisis could turn out to be the tipping point of the neoliberal model and extreme forms of laissez-faire economics. The progression could be seen before the crisis in the form of civil unrests and struggles between nations. The vulnerability of the system was clearly illustrated with the strong dependency on global collaborations and complicated supply chains. Now, companies might want to restructure their business models towards a stronger domestic focus with shorter supply chains and reduced levels of outsourcing in case a similar situation returns. As a shift in consumer behavior already took place and is not unlikely to stay that way or develop even more, depending on the further progress, organizations need to adapt their strategies according to the new reality. As the crises of the past proved, despite their harmful nature, they also offer opportunities to grow. The potentials for diversification need to be utilized in order to achieve stronger positions in the market which also boost the success in the post-crisis situation. For instance, Uber and Airbnb made the best of the situation by creating platforms that met the demand in the succeeding years of the last financial crisis and managed to sustain their success by developing into leading companies in their respective sectors.

Now, the attention needs to be on ideas that serve as potential solutions for current and future problems. Technology companies seem to become even more powerful than they were before due to the attempts of trying to reduce personal contact as much as possible in every economic segment. As the analysis of the situation highlighted, it is not unlikely, that a long-term shift in consumer behavior has already taken place, influencing the economic landscape in a very drastic way. Companies such as Microsoft Teams and Zoom strongly benefitted from the crisis but apart from that, other industries can adapt their products to become digital as well. In addition to that, it is an opportunity to pursue the concept of working remotely from home in the long term because it has proven itself and can benefit employers and employees likewise. This aspect might even develop to a key aspect for applicants to consider an employer while being on the search for a job. It is also recommended to join forces in the form of collaborations that provide possibilities for benefiting in a mutual way. If the needed resources for a stronger digitalization are not available, partnerships are an effective way to proceed, especially when solutions are required quickly.

While doing so, organizations should also take additional changes in consumer behavior into account. The crisis led to an increased sensitivity for the broader picture because people realized the vulnerability of the world, they live in. Therefore, the consideration of corporate social responsibility needs to be emphasized and communicated even more than before the surfacing of COVID-19 because consumers integrate a variety of factors into their decision-making process that exceed the core characteristics of a product. Besides that, companies need to avoid coming to conclusions based on survivorship bias. The problem is, that only things and actions that turn out to be successful get considered in future decisions. However, it is advisable to also look at the ones who failed and analyze the reasons for that. By doing that, not only the strong aspects that allowed the successful entities to survive get strengthened even more, but also the ones that led to the failure of the unsuccessful ones can be upgraded. Moreover, the focus should not only lie on improving aspects that caused trouble in this scenario, but also on possible other negative developments because the next crisis can cause considerably different issues that challenge organizations in diverse ways. With the changed economic landscape and dissimilar situations regarding the Coronavirus in different geographic areas, new challenges will arise, and risks might also develop more locally. Even though, there 
are numerous problems that seem to be very urgent now, risk management should not be neglected because the occurrence of the next threat is only a matter of time.

\section{GENERAL CONCLUSIONS AND FUTURE RESEARCH}

The aim of this paper was to analyze the approaches of risk management that are applied in the business world and to examine whether the strong focus on data and statistics leads to insufficient decisions that get reflected in poor results. For this purpose, crises of the past as well as selected companies and their actions in those times were analyzed in detail with the objective of being able to identify patterns and to draw conclusions for future events. In addition to that, risk management was viewed with respect to the current COVID-19 crisis from which advice for action got derived as well. This section summarizes the most important findings and points out the limitations of this study and gives recommendations for future research.

The main finding of this paper is that the approaches towards risk are not as granular as they could be but simultaneously are not the pivotal cause for bad outcomes despite the conduct of risk management. Even though some systems require adaptations in order to keep up with the constant changes in the respective environments, the analysis shows that most of them can anticipate negative developments. By doing so, they pave the way for sensible decisions and serve as an effective method to prevent a crisis from continuously becoming worse. Managing risks is more than just analyzing data and depends on the ability of individuals to see the bigger picture. The real reason for risk management approaches failing turned out to be the decisions of individuals who base their judgment on behavioral traits that imply subjective factors that negatively bias decisions. Even if the outcomes of risk management systems in place indicate undesirable developments it is still within the realms of possibility that individuals resist to follow the most sensible conclusions in favor of personal interests. Although in case of COVID-19 it was difficult to foresee the catastrophe unfold, preparations could have been made more thoroughly. Nevertheless, this situation will most probably have more intense learning effects due to the extreme extent it has impacted society. Besides that, the relevance and possibilities for strategic management to improve existing risk management processes became clear in the contexts that were discussed. Having said that, the concepts of strategic management also need to be revised regularly because of the continuously changing environment and following reduction of planning horizons.

Finally, in preparing this paper, conducting direct interviews with relevant people from the respective sectors would have been useful but pandemic constraints limited the options and, given the nature of the topic, people were also reluctant to share their insights, consequently we have had to rely on published material. The factfulness and credibility of the published material must always be taken into account and, for that reasons, further research regarding the psychological factors that lead to the behavior of individuals as described in an earlier section of the paper will be needed to verify the results. Moreover, as the Coronavirus is not yet erased and the uncertainty regarding future developments is comparably high, the examination of it is partially incomplete because it only considers information that is available up until this point in time. Future research should focus on conducting an analysis once the situation has unfolded completely. It will be interesting to investigate further changes in consumer behavior in the long term and the ways it develops along the process. This also includes people's attitudes towards risk and possible drivers, such as money or certain beliefs, in favor of risky behavior. Additionally, investigating future takes towards the neoliberal economic model and possible changes in existing business models will be as much of interest as the analysis of the viability of different industries and companies in diverse geographic regions. 


\section{REFERENCES}

Arvinth, K. (2015). VW Scandal: Carmaker Was Warned by Bosch About Test-Rigging Software in 2007 [online]. International Business Times. Retrieved July 3, 2020, from https://www.ibtimes.co.uk/vw-scandal-carmaker-was-warned-about-test-rigging-software-20071521442

Bannas, G., \& Germis, C. (2015). VW und die Politik: Ein tolles Stück Deutschland [online]. Frankfurter Allgemeine Zeitung. Retrieved July 1, 2020, from https://www.faz.net/aktuell/politik/inland/vwund-die-politik-ein-tolles-stueck-deutschland-13821985.html

BBC News. (1998). Business: The Economy Russian Bank Assets 'Seized' [online]. Retrieved June 28, 2020, from http://news.bbc.co.uk/2/hi/-business/179439.stm

Bergermann, M. (2018). Mitarbeiter warnte VW schon 2011 vor Abgasmanipulation [online]. WirtschaftsWoche. Retrieved July 3, 2020, from https://www.wiwo.de/unternehmen/auto/dieselskandal-mitarbeiter-warnte-vw-schon-2011-vor-abgasmanipulationen/23650184.html

Compeon.de. (2020). Eigenkapitalquote [online]. Retrieved July 3, 2020, from https://www.c-ompeon.de/glossar/eigekapitalquote/

Cramer, C. (2002). Homo Economicus Goes to War: Methodological Individualism, Rational Choice and the Political Economy of War. World Development, 30(11), 1845-1864.

Davies, R. (2016). VW Boss Who Quit Over Emissions Scandal Gets £13m Pay Package [online]. The Guardian. Retrieved July 3, 2020, from https://www.theguardian.com/business/2016/apr/28/departed-volkswagen-boss-martin-winterkorn-gets-paid-13m

Deutscher Bundestag. (2013). Drucksache 17/12051 [online]. Retrieved July 22, 2020, from https://dipbt.bundestag.de/dip21/btd/17/120/1712051.pdf

Diamond, J. (2011). Collapse: How Societies Choose to Fail or Survive. New York: Penguin Books.

Diamond, J. (2019). Upheaval: How Nations Cope with Crisis and Change. New York: Little, Brown and Company.

Fessler, P., \& Hinsch, S. (2013). Wie funktioniert Wirtschaft? Eine kritische Einführung. Wien: Promedia Verlag.

Focus.de. (2010). VW verkaufte bis November mehr Autos als 2009 [online]. Retrieved July 3, 2020, from https://www.focus.de/finanzen/news/auto-vw-verkaufte-bis-november-mehr-autos-als2009 aid_580510.html

Forster, S. (2016). Was ist eine gute Eigenkapitalquote? [online] NeuKurs. Retrieved July 3, 2020, from https://neukurs.com/blog/fachwissen/wie-hoch-ist-ihr-eigenkapitalquote/

Gass, N. (2015). Lehman Brothers Ex-CEO Blames Everyone Else for Financial Crisis [online]. Politico. Retrieved July 25, 2020, from https://www.politico.com/story/2015/05/richard-dick-fuld-lehmanbrothers-financial-crisis-118374

Gilbert, D. (2006). If Only Gay Sex Caused Global Warming [online]. Los Angeles Times. Retrieved July 28, 2020, from https://www.latimes.com/archives/la-xpm-2006-jul-02-op-gilbert2-story.html

Global Preparedness Monitoring Board. (2019). A World at Risk: Annual Report on Global Preparedness for Health Emergencies [online]. Retrieved July 16, 2020, from https://apps.who.int/gpmb/assets/annual_report/GPMB_annualreport_2019.pdf

Hotten, R. (2015). Volkswagen: The Scandal Explained [online]. BBC News. July 3, 2020, from https://www.bbc.com/news/business-34324772

Kahneman, D., \& Tversky, A. (1979). Prospect Theory: An Analysis of Decision under Risk. Journal of the Econometric Society, 47(2), 263-291.

McDonald, C. (2013). Lehman Couldn't Handle the Risk Management Truth [online]. CFO. Retrieved June 28, 2020, from https://www.cfo.com/risk-management/2013/02/lehman-couldnt-handle-therisk-management-truth/

McLeod, S. (2017). The Milgram Shock Experiment [online]. SimplyPsychology. Retrieved July 28, 2020, from https://www.simplypsychology.org/milgram.html 
Pearl, J., \& Mackenzie, D. (2018). The Book of Why: The New Science of Cause and Effect. New York: Basic Books.

Pompeo, J. (2020). The Hedge Fund Vampire That Bleeds Newspapers Dry Now Has the Chicago Tribune by the Throat [online]. Vanity Fair. Retrieved July 31, 2020, from https://www.vanityfair.com/news/2020/02/hedge-fund-vampire-alden-global-capital-that-bleeds-newspapers-dryhas-chicago-tribune-by-the-throat

Reuters Staff. (2015). VW Says Sold First UK Vehicle with Emission Test Rigging Software in 2008 [online]. Reuters. Retrieved July 3, 2020, from https://uk.reuters.com/article/volkswagen-emissions/vw-says-sold-first-uk-vehicle-with-emission-test-rigging-software-in-2008idUKU8N10Z00520151012

RKI. (2019). Influenza-Pandemieplanung [online]. Retrieved July 22, 2020, from https://www.rki.de/DE/Content/InfAZ/I/Influenza/Pandemieplanung/Pandemieplanung Node.html

Slovic, P., Fischhoff, B., \& Lichtenstein, S. (1982). Why Study Risk Perception? Risk Analysis, 2(2), 8393.

Sun, L. (2018). Top White House Official in Charge of Pandemic Response Exits Abruptly [online]. The Washington Post. Retrieved July 9, 2020, from https://www.washingtonpost.com/news/to-yourhealth/wp/-2018/05/10/top-white-house-official-in-charge-of-pandemic-response-exits-abruptly/

The World Bank. (2020). Hospital Beds (per 1,000 people) - Germany [online]. Retrieved July 22, 2020, from https://data.worldbank.org/indicator/SH-.MED.BEDS.ZS?locations=DE\&most_recent value desc $=$ true

The World Bank. (2020a). Physicians (per 1,000 people) - Germany [online]. Retrieved July 22, 2020, from https://data.worldbank.org/indicator/SH.MED.PHYS.ZS?locations=DE\&most_recent value desc $=$ true

US Intelligence Community (IC). (2019). Statement for the Record: Worldwide Threat Assessment of the US Intelligence Community [online]. Retrieved July 9, 2020, from https://www.dni.gov/files/ODNI/documents/2019-ATA-SFR---SSCI.pdf

Valukas, A. (2010). Examiner's Report [online]. United States Bankruptcy Court Southern District of New York. Retrieved July 28, 2020, from http://web.stanford.edu/- jbulow/Lehmandocs/VOUME\%201.p-df

Volkswagen. (2006). Annual Report 2006 [online]. Retrieved July 3, 2020, from https://cw.volkswagenag.com/presence/konzern/images/teaser/history/chronik/annual-report/2006-Annual-Report.pdf

Volkswagen. (2007). Annual Report 2007 [online]. Retrieved July 3, 2020, from https://ddd.uab.cat/pub/infanu/146223/iaVOLKSWAGENa2007ieng.pdf

Volkswagen. (2016). Annual Report 2016 [online]. Retrieved July 3, 2020, from https://www.volkswagenag.com/presence/investorrelation/publications/annual-reports/2017/volkswagen/en/Y_2016_e.pdf

Volkswagen. (2019). Annual Report 2019 [online]. Retrieved July 3, 2020, from https://www.volkswagenag.com/presence/investorrelation/publications/annual-reports/2020/volkswagen/Y_2019_e.pdf

Volkswagen. (2020). History [online]. Retrieved July 1, 2020, from https://www.volkswagenag.com/en/group/history.html

Weber, J., Weißenberger, B., \& Liekweg, A. (2001). Risk Tracking \& Reporting: Ein umfassender Ansatz unternehmerischen Chancen- und Risikomanagements. In U. Götze, K. Henselmann, \& B. Mikus, Risikomanagement (pp. 47-65). Heidelberg: Physica-Verlag.

Webster, R. (2018). Flu Hunter: Unlocking the Secrets of a Virus. Dunedin: Otago University Press.

Wharton University. (2018). Not Too Big to Fail: Why Lehman Had to Go Bankrupt [online]. Retrieved June 28, 2020, from https://knowledge.wharton.upenn.edu/article/the-good-reasons-why-lehmanfailed/

Wiggins, R., Piontek, T., \& Metrick, A. (2014). The Lehman Brothers Bankruptcy A: Overview [online]. Yale Program on Financial Stability Case Study 2014-3A-V1. Retrieved June 28, 2020, from https://som.yale.edu/sites/default/files/files/001-2014-3A-V1-LehmanBrothers-A-REVA.pdf 
World Health Organization (WHO). (1999). Influenza Pandemic Plan. The Role of WHO and Guideline for National and Regional Planning [online]. Retrieved July 9, 2020, from https://apps.who.int/iris/bitstream/handle/10665/66155/WHO_CDS_CSR_EDC_99.1.pdf?sequence $=1 \&$ isAllowed $=y$

World Health Organization (WHO). (2017). Global Influenza Programme: Pandemic Influenza Risk Management [online]. Retrieved July 9, 2020, from https://apps.who.int/iris/bitstream/handle/10665/259893-/WHO-WHE-IHM-GIP-2017.1-eng.pdf;jsessionid=FF0E44DE342CCEF9F0A31E1EFB14C8E8?sequence $=1$

World Health Organization (WHO). (2017a). Pandemic Influenza Preparedness (PIP) Framework [online]. Retrieved July 9, 2020, from https://www.who.int/influenza/pip/What-IsPIP.pdf

World Health Organization (WHO). (2020). Alphabetical List of WHO Member States [online]. Retrieved July 9, 2020, from https://www.who.in-t/choice/demography/by_country/en/ 